\title{
On the relation between weather-related disaster impacts, vulnerability and climate change
}

\author{
Hans Visser • Arthur C. Petersen • Willem Ligtvoet
}

Received: 8 August 2013 / Accepted: 9 June 2014 / Published online: 15 July 2014

C) The Author(s) 2014. This article is published with open access at Springerlink.com

\begin{abstract}
Disasters such as floods, storms, heatwaves and droughts can have enormous implications for health, the environment and economic development. In this article, we address the question of how climate change might have influenced the impact of weather-related disasters. This relation is not straightforward, since disaster burden is not influenced by weather and climate events alone - other drivers are growth in population and wealth, and changes in vulnerability. We normalized disaster impacts, analyzed trends in the data and compared them with trends in extreme weather and climate events and vulnerability, following a 3 by 4 by 3 set-up, with three disaster burden categories, four regions and three extreme weather event categories. The trends in normalized disaster impacts show large differences between regions and weather event categories. Despite these variations, our overall conclusion is that the increasing exposure of people and economic assets is the major cause of increasing trends in disaster impacts. This holds for long-term trends in economic losses as well as the number of people affected. We also found similar, though more qualitative, results for the number of people killed; in all three cases, the role played by climate change cannot be excluded. Furthermore, we found that trends in historic vulnerability tend to be stable over time, despite adaptation measures taken by countries. Based on these findings, we derived disaster impact projections for the coming decades. We argue that projections beyond 2030 are too uncertain, not only due to unknown changes in vulnerability, but also due to increasing non-stationarities in normalization relations.
\end{abstract}

Electronic supplementary material The online version of this article (doi:10.1007/s10584-014-1179-z) contains supplementary material, which is available to authorized users.

H. Visser $(\bowtie) \cdot$ A. C. Petersen $\cdot$ W. Ligtvoet

PBL Netherlands Environmental Assessment Agency, Bilthoven, The Netherlands e-mail: Hans.Visser@pbl.nl

A. C. Petersen

Centre for the Analysis of Time Series, London School of Economics and Political Science (LSE),

London, UK

A. C. Petersen

Institute for Environmental Studies (IVM), VU University, Amsterdam, The Netherlands 


\section{Introduction}

Weather-related disasters such as floods, storms, heatwaves and droughts can have enormous implications for health, the environment and economic development. Historic examples of severe disaster impacts are (1) the drought in Ethiopia and Sudan that resulted in over 400,000 deaths through famine in 1983, (2) the drought in India and floods in China that affected 450 million people in 2002, and (3) Hurricane Katrina and subsequent flooding in the US that led to economic damage valued at 140 billion $\mathrm{USD}_{2010}$.

In the media and among the general public, links between individual disasters and climate change are quickly made. Such connections seem logical, since weather extremes are the drivers of disaster impacts, and the global climate is changing (IPCC 2013); however, connections between disasters and climate change are often made too readily. Often overlooked is the fact that disaster burden is not only steered by weather extremes and changes in their intensity and frequency. Other influencing factors are socioeconomic in nature such as changes in wealth, population and vulnerability over the same period of time (IPCC-SREX 2012, see their figure 1-1; IPCC 2014, see their figure SPM.1).

A number of studies have been carried out recently to shed more light on the relationship between disasters and climate change (see Neumayer and Barthel 2011; Bouwer 2011a; Barthel and Neumayer 2012, and references therein). These studies corrected economic losses for changes in wealth (approximated by GDP) and population size. This method, called 'normalization', corrects for the fact that a certain extreme weather event will result in proportionally higher losses if the population is growing and/or GDP is rising.

The general idea behind normalization is that if we want to detect a climate signal in disaster losses, the role of changes in wealth and population should be ruled out; however, this is complicated by the fact that changes in vulnerability may also play a role. More formally, the relation between a disaster burden indicator $D_{\mathrm{t}}$ and its drivers can be written as:

$$
D_{\mathrm{t}}=\mathrm{f}\left(E_{\mathrm{t}}, C_{\mathrm{t}}, V_{\mathrm{t}}\right) \approx E_{\mathrm{t}} * \mathrm{~g}\left(C_{\mathrm{t}}, V_{\mathrm{t}}\right)
$$

where $E_{\mathrm{t}}$ is the exposure of a certain region to weather extremes, $C_{\mathrm{t}}$ an indicator for the intensity of extreme weather or climate events, and $V_{t}$ the vulnerability of the region (definitions given in Section 2.2). Subsequently, a normalized disaster burden indicator $D_{\mathrm{t}}^{\prime}$ is defined as $D_{\mathrm{t}}^{\prime}=D_{\mathrm{t}} / E_{\mathrm{t}}$ and is better suited to analyze the specific role of climate change.

With regard to economic losses, it has been found that historic trends in $D_{\mathrm{t}}^{\prime}$ follow a stabilized, constant pattern, both at national and regional scales. Bouwer (2011a) summarizes normalized curves from 22 disaster loss studies and concludes that these studies show no trends in losses when corrected for changes (increases) in population and capital at risk. Global- and continental-scale studies carried out by Neumayer and Barthel (2011) find no significant upward trends in normalized disaster damage over the 1980-2009 period-not globally, regionally, for specific disasters or for specific disasters in specific regions. However, they note that as long as the vulnerability term $V_{\mathrm{t}}$ in Eq. (1) is unknown, the role of climate change in disaster losses cannot be ruled out. This latter point has also been discussed by Nicholls (2011) and Bouwer (2011b) in a commentary on Bouwer (2011a).

Nicholls argues that only if improvements in weather forecasting and changes in building regulations and techniques have failed to reduce economic vulnerability to weather hazards can the conclusion be drawn that the absence of an increase in normalized economic losses is evidence that climate change has not increased losses from such hazards. Bouwer (2011b) replies that only a few quantifications of the avoided losses resulting from vulnerability reduction are available. Furthermore, a human contribution to trends in most of the large- 
scale weather-related hazards that were addressed in his study such as extratropical storms and floods, has not been found. These two arguments underpin the conclusion that changes in population and wealth are the main drivers of increasing impacts of weather-related disastersthe term $E_{\mathrm{t}}$ in Eq. (1).

Since weather-related disasters have high societal consequences, the 'Nicholls-Bouwer discussion' is of high importance and requires further elaboration. In this article, we follow the lines of the analyses given in Bouwer (2011a) and Neumayer and Barthel (2011) and the subsequent discussion in more detail by extending their approach to impacts other than economic losses, namely the number of people affected and the number of people killed. These latter two indicators are underexposed in the literature. Furthermore, we analyze normalized disaster impacts at large regional scales: globally, in developed countries (OECD countries), in upcoming economies (the group of BRIICS countries) and in developing countries (the remaining countries). Finally, we analyze what type of weather extremes or weather phenomena that contribute most to normalized disaster impacts and summarize what we know about trends in these extremes or phenomena - the term $C_{\mathrm{t}}$ in Eq. (1). Trends in vulnerability are also discussed (the term $V_{\mathrm{t}}$ in Eq. 1). As in the 'Nicholls-Bouwer discussion', we evaluate whether trends in normalized disaster impacts are consistent with trends in climate drivers and vulnerability.

This article is organized as follows: data and methods are given in Section 2, where we also describe the CRED database and provide methodological aspects (normalization procedure and trend estimation). We present the normalization results for three disaster burden indicators in Section 3, and evaluate which type of weather extremes contribute most to these normalized series in Section 4. In Section 5, we evaluate whether trends in normalized disaster burden are consistent with trends in climate drivers and vulnerability. Implications for future projections are discussed in Section 6 and conclusions are given in Section 7. Details on the CRED disaster database and the statistical approach used for trend estimation are given in the electronic supplementary material (ESM).

\section{Data and methods}

\subsection{EM-DAT emergency database}

All the analyses in this article are based on the EM-DAT emergency database. This database is open source and maintained by the World Health Organization (WHO) and the Centre for Research on the Epidemiology of Disasters (CRED) at the University of Louvain, Belgium (Guha-Sapir et al. 2012). Comparable databases are NatCat (Munich Re) and Sigma (Swiss $\mathrm{Re}$ ), which are maintained on a commercial basis. The EM-DAT database contains disaster events from 1900 onwards, presented on a country basis. Details and reliability aspects are given in Appendix A of ESM. CRED applies the following classification for weather-related disaster events (Below et al. 2009):

- Meteorological events, including hurricanes (typhoons), extratropical storms and local storms

- Hydrological events, including coastal and fluvial floods, flash floods and mass movements

- Climatological events, including cold waves, heatwaves, other extreme temperature events, drought and wildfire 
We have adopted this terminology in this article (although it is rather arbitrary why a storm is denoted as a meteorological event and a heatwave as a climatological event). It should be noted that the term 'natural disasters' is used in the literature if geophysical events are also included (earthquakes, tsunamis and volcano eruptions). These latter events are excluded here.

The EM-DAT database provides three disaster impact indicators for each disaster event: economic losses, the number of people affected and the number of people killed. Here, economic losses are direct damage costs and a direct consequence of weather or climate events. The number of people affected is the sum of people injured, people needing immediate assistance for shelter and people requiring immediate assistance during a period of emergency (this may include displaced or evacuated people; see ESM for more detailed definitions).

We aggregated country information on disasters to three economic regions: OECD countries, BRIICS countries (Brazil, Russia, India, Indonesia, China and South Africa) and the remaining countries, denoted hereafter as Rest of World (RoW) countries. OECD countries can be seen as the developed countries, BRIICS countries as upcoming economies and RoW as the developing countries. An example of these annually aggregated data is given in Fig. 1, in which extreme disasters are highlighted using catchwords. The panels show large differences across disaster indicators and regions: economic losses are largest in the OECD countries, the number of people affected is largest in the BRIICS countries and the number of people killed is largest in the RoW countries.

\subsection{Normalization}

As described in the introduction, disaster burden can be formulated as a function of exposure, climate drivers and vulnerability ${ }^{1}$. Exposure can be described as a function of population size and wealth, or

$$
D_{\mathrm{t}} \approx E_{\mathrm{t}} * \mathrm{~g}\left(C_{\mathrm{t}}, V_{\mathrm{t}}\right)=\mathrm{h}\left(W_{\mathrm{t}}, P_{\mathrm{t}}\right) * \mathrm{~g}\left(C_{\mathrm{t}}, V_{\mathrm{t}}\right)
$$

where $W_{\mathrm{t}}$ is an indicator for wealth; here GDP and expressed as PPP (purchasing power parity), and $P_{\mathrm{t}}$ is the population size.

For normalization purposes we formulated the following multiplicative models:

$$
\begin{aligned}
& \text { economic Losses : } L_{\mathrm{j}, \mathrm{t}}=W_{\mathrm{j}, \mathrm{t}} * g_{\mathrm{j}, 1}\left(C_{\mathrm{j}, \mathrm{t}}, V_{\mathrm{j}, \mathrm{t}}\right) \\
& \text { people Affected : } A_{\mathrm{j}, \mathrm{t}}=P_{\mathrm{j}, \mathrm{t}} * g_{\mathrm{j}, 2}\left(C_{\mathrm{j}, \mathrm{t}}, V_{\mathrm{j}, \mathrm{t}}\right) \\
& \text { people Killed : } K_{\mathrm{j}, \mathrm{t}}=P_{\mathrm{j}, \mathrm{t}} * g_{\mathrm{j}, 3}\left(C_{\mathrm{j}, \mathrm{t}}, V_{\mathrm{j}, \mathrm{t}}\right)
\end{aligned}
$$

with the subscript $\mathrm{j}$ denoting one of the regions 'OECD', 'BRIICS', 'RoW' or 'Global'. For all three equations, it holds that the indicator sum of regions equals 'Global'. The functions $g_{\mathrm{j}, 1}$, $g_{\mathrm{j}, 2}$ and $g_{\mathrm{j}, 3}$ are assumed to be monotonic with respect to their arguments; in other words, disaster burden will not decrease if weather events become more extreme in the region of interest and/or the region becomes more vulnerable. We note that Eq. (3a) equals the

\footnotetext{
${ }^{1}$ We followed the definitions given in IPCC-SREX (2012). The vulnerability of countries or regions is defined as their susceptibility or predisposition to loss and damage to human beings and livelihoods. Vulnerability will decrease due to disaster risk reduction measures (adaptation) but increase if political instabilities occur (riots, civil war, etc.). Note: Birkmann (2013, see Chap. 23) gives 39 definitions of vulnerability.
} 

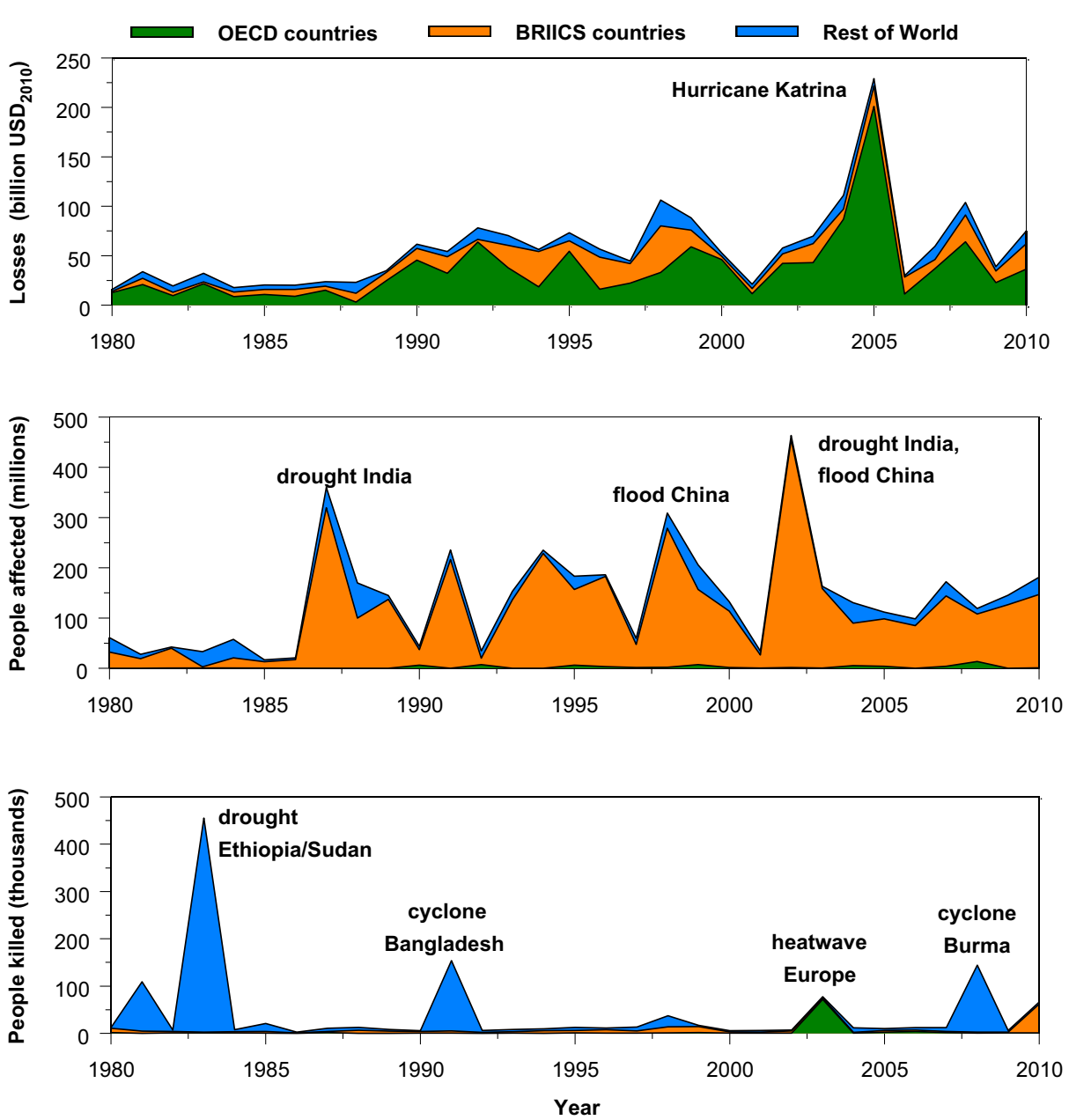

Fig. 1 Three types of disaster burden, stacked to three economic regions (OECD countries, BRIICS countries and Rest of World). The time evolution of economic losses is shown in the upper panel, the number of people affected in the middle panel and the number of people killed in the lower panel. Individual disasters with large impacts are highlighted using catchwords. Disaster data were aggregated from the CRED EM-DAT database

formulation of Neumayer and Barthel (2011; Eqs. (1) and (4)). Now, normalized indicators are simply defined as:

$$
L_{\mathrm{j}, \mathrm{t}}{ }^{\prime}=L_{\mathrm{j}, \mathrm{t}} / W_{\mathrm{j}, \mathrm{t}}, A_{\mathrm{j}, \mathrm{t}}{ }^{\prime}=A_{\mathrm{j}, \mathrm{t}} / P_{\mathrm{j}, \mathrm{t}} \text { and } K_{\mathrm{j}, \mathrm{t}}{ }^{\prime}=K_{\mathrm{j}, \mathrm{t}} / P_{\mathrm{j}, \mathrm{t}}
$$

In Section 3 we analyze the trends in $L_{\mathrm{j}, \mathrm{t}}{ }^{\prime}, A_{\mathrm{j}, \mathrm{t}^{\prime}}$ and $K_{\mathrm{j}, \mathrm{t}}{ }^{\prime}$; the relative role of meteorological, hydrological and climatological events are given in Section 4. Normalization can be performed in various ways. Using Eqs. (3a)-(3c), we followed the method proposed by Neumayer and Barthel (2011), see their equation 4. Other functional methods are given by Pielke et al. (2008) and Neumayer and Barthel (2011, see their equation 1). Once a functional method has been chosen, the relations given in Eq. (4) can be calculated on much smaller spatial scales and summed afterwards to the region of interest. Neumayer and Barthel applied this approach for 
economic losses by defining gridded affected areas with corresponding GDP data. This approach is not followed in this study.

Data for $W_{\mathrm{j}, \mathrm{t}}$ and $P_{\mathrm{j}, \mathrm{t}}$ are taken from OECD (2012, see Chap. 2) and further described in Visser et al. (2012).

\subsection{Trend estimation}

There are many methods for estimating trends in historic data (Chandler and Scott 2011; Visser and Petersen 2012); however, generally speaking, there is no best method as this depends on the characteristics selected. We have chosen here to apply a model from the class of structural time series models, in combination with the Kalman filter: the integrated random walk (IRW). The advantage of this model is its ability to generate uncertainties for trend statistics. More specifically, this trend approach generates uncertainties for trend estimates $\mu_{\mathrm{t}}$ and any trend difference $\left(\mu_{\mathrm{t}}-\mu_{\mathrm{s}}\right)$. Furthermore, the OLS linear trend, often applied in disaster research, is a special case of the IRW trend approach. The IRW trend can therefore be seen as a natural extension of the straight line, in which the full uncertainty information is retained (Visser 2004; see Appendix B of ESM for details). The importance of choosing a particular trend method in disaster research has been illustrated by Visser and Petersen (2012, their figure 7a and b).

An example for the number of people affected in BRIICS countries is given in Fig. 2. Since the data are skewed to higher values, we log-transformed the original data $y_{\mathrm{t}}: z_{\mathrm{t}}=\log \left(y_{\mathrm{t}}\right)$. After trend estimation, the trend estimates were back-transformed by taking exponentials (Appendix $\mathrm{B}$ of ESM). One consequence of the transformation is that any trend difference $\left(\mu_{\mathrm{t}}-\mu_{\mathrm{s}}\right)$ estimated for $z_{\mathrm{t}}$, transforms to a trend ratio $\left(\mu_{\mathrm{t}} / \mu_{\mathrm{s}}\right)$ for $y_{\mathrm{t}}$. The upper panel shows the normalized data along with the IRW trend estimate and $95 \%$ confidence limits. The lower panel shows trend ratios $\left(\mu_{2010} / \mu_{\mathrm{t}}\right)$, along with $95 \%$ confidence limits. This panel shows three important findings: (1) the trend ratio over the full sample period is high: $\left(\mu_{2010} / \mu_{1980}\right)=5.2$, (2) the $95 \%$ confidence limits are wide: (1.5-18.7), and (3) the rise in the trend occurs mainly over the first 5 years: the trend ratios $\left(\mu_{2010} / \mu_{\mathrm{t}}\right)$ are significant for the $1981-1985$ period only $(\alpha=0.05)^{2}$.

IRW trend estimates do not give satisfactory results for all the disaster time series, due to outliers in the data. For these cases, we applied extreme value models (Coles 2001) and a nonstatistical trend estimation technique known as Lowess estimators (Chandler and Scott 2011, see their section 4.3.1). We used the S-PLUS 8.1 software for these analyses.

\section{Trends in normalized disaster burden}

In this section we present normalized disaster burdens as defined in Eq. (4), along with IRW trends for these data. We note that trends in non-normalized disaster burden have been treated in Visser et al. ( 2012, see their figures 3.2, 5.1, 5.2 and 5.3).

\subsection{Economic losses $L_{\mathrm{j}, \mathrm{t}^{\prime}}$}

We estimated trends and uncertainties for normalized economic losses $L_{\mathrm{j}, \mathrm{t}}{ }^{\prime}$ as described in Section 2.3. Data and IRW trends are given in Fig. 3 (upper panel) for all four regions j: Global, OECD, BRIICS and RoW. Due to outliers in the data, we log-transformed all data

\footnotetext{
${ }^{2}$ With 'significance at $\alpha=0.05$ ', the following two-sided test is performed: $H_{0}$ : $\left(\mu_{2010} / \mu_{\mathrm{t}}\right)=1.0$ versus $H_{1}:\left(\mu_{2010} / \mu_{\mathrm{t}}\right) \neq 1.0$. In this example, the null hypothesis is rejected for all ratios with ' $\mathrm{t}$ ' between 1980 and 1985, and accepted otherwise.
} 

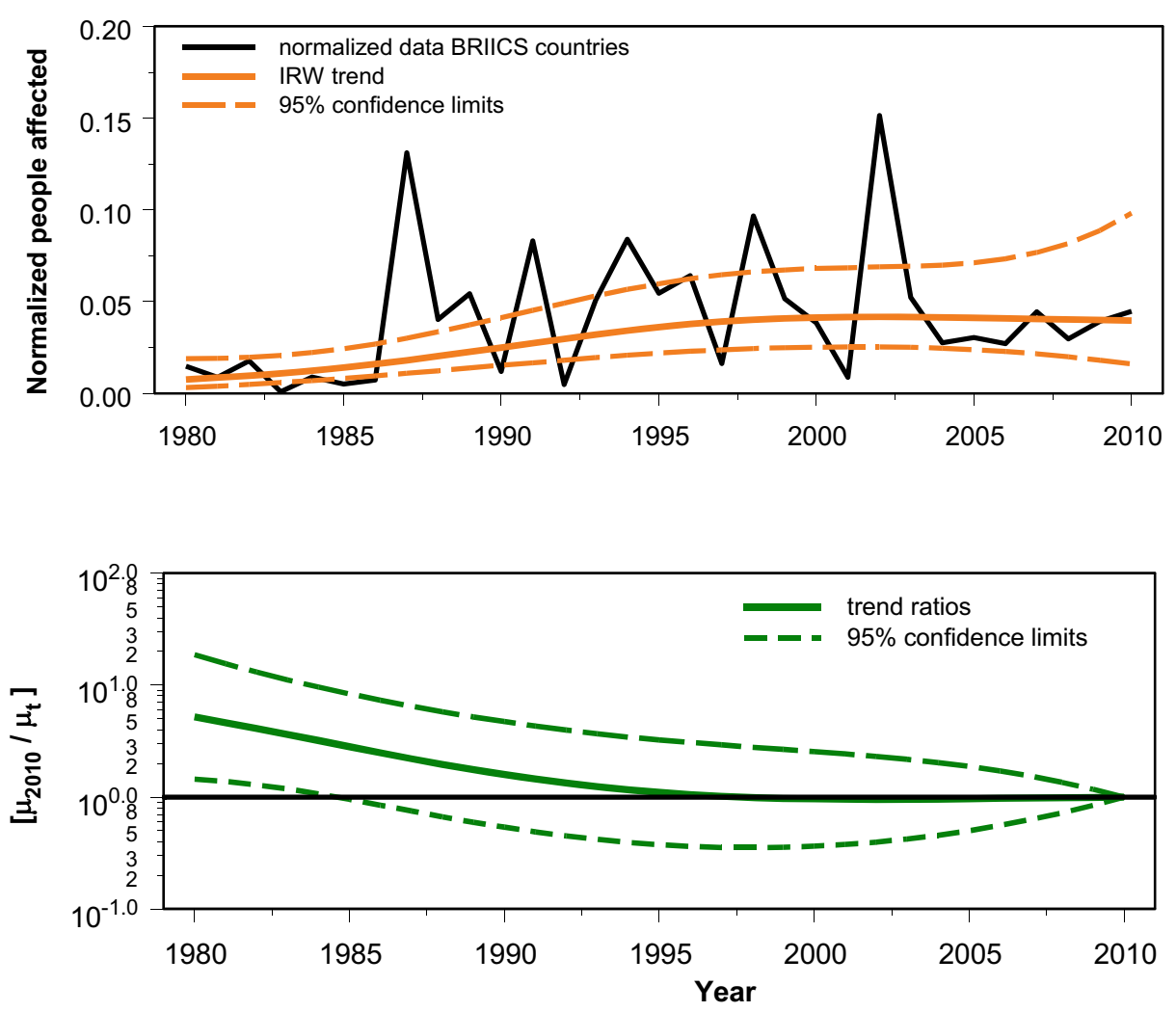

Fig. 2 Number of people affected in BRIICS countries after normalization for population size (upper panel). Both data and IRW trend are given, along with $95 \%$ pointwise confidence limits for the trend (dashed lines). The lower panel shows trend ratios $\left(\mu_{2010} / \mu_{\mathrm{t}}\right)$, drawn on a logarithmic scale. The line $10^{0.0}$ represents no change (trend ratio equal to 1.0 )

prior to estimating IRW trends. The trends shown were back-transformed by taking exponentials as explained in Section 2.3. All four trends show a stabilized, constant pattern. As an example, we give the trend ratios $\left(\mu_{2010} / \mu_{1980}\right): 1.5(0.7-3.0)$ for the global trend, with a $95 \%$ confidence limit between brackets, $2.0(0.8-5.1)$ for OECD countries, $1.6(0.6-4.4)$ for BRIICS countries and $0.66(0.31-1.4)$ for RoW countries. None of these trend ratios are therefore statistically different from 1.0; in other words, there was no significant change over the full sample period $(1980-2010 ; \alpha=0.05)^{3}$.

\subsection{Number of people affected $A_{\mathrm{j},{ }^{\prime}}$}

Data and IRW trends for the normalized number of people affected $A_{\mathrm{j},{ }^{\prime}}$ are shown in Fig. 3 (lower panel). As for the $L_{\mathrm{j}, \mathrm{t}}{ }^{\prime}$ data, we log-transformed prior to estimating IRW trends, compensating for skewness in the data. There appears to be no significant trend for two of the four regions $(\alpha=0.05)^{4}$ : global and RoW countries (black and blue lines). Examples are the

\footnotetext{
${ }^{3}$ Ibid.

${ }^{4}$ Ibid.
} 

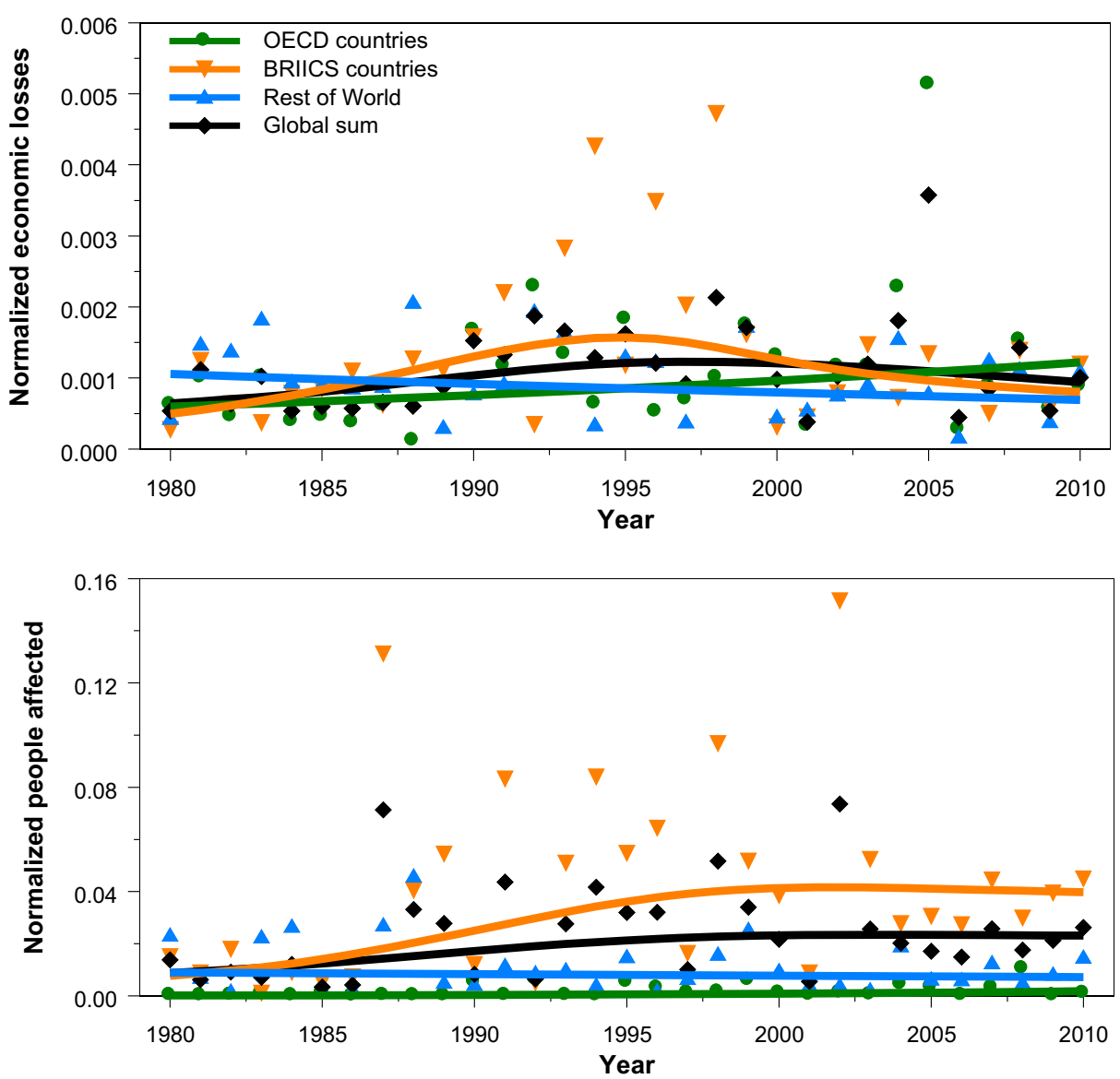

Fig. 3 Economic losses normalized for wealth (upper panel) and the number of people affected normalized for population size (lower panel). Sample period is 1980-2010. Solid lines are IRW trends for the corresponding data. The orange data and trend in the lower panel equal those presented in the upper panel of Fig. 2

ratios $\left(\mu_{2010} / \mu_{1980}\right)$, which are $2.6(0.9-7.3)$ for the global trend and $0.80(0.30-2.11)$ for the RoW countries.

Trend ratios for OECD and BRIICS also stabilize, but not from 1980 onwards. The situation in BRIICS countries is shown in Fig. 2. As can be seen, the trend stabilizes from 1985 onwards. Similarly, the trend for OECD countries stabilizes from 1982 onwards. The ratios $\left(\mu_{2010} / \mu_{1980}\right)$ are $13.8(1.7-112)$ for OECD countries and $5.2(1.5-18.7)$ for BRIICS countries. We note that the OECD ratio of 13.8 is very high; however, not in terms of absolute numbers. The trend value $\mu_{2010}$ for BRIICS countries is 0.040 , and 0.002 for OECD countries (thus a factor of 20 lower).

\subsection{Number of people killed $K_{\mathrm{j},{ }^{\prime}}$}

Data and trends for the normalized number of people killed $K_{\mathrm{j}, \mathrm{t}}$ ' are shown in Fig. 4 (upper panel). The trends were not estimated using IRW trends, as with $L_{\mathrm{j}, \mathrm{t}}{ }^{\prime}$ and $A_{\mathrm{j}, \mathrm{t}}{ }^{\prime}$, as none of the IRW trends estimated for these four regional datasets yielded acceptable white noise 
innovation data (this whiteness of noise process is a prerequisite for the time series models to hold). This failure is explained by the presence of outliers in these datasets, as can be seen in the lower panel of Fig. 4. We also applied a Gumble and a GEV distribution to the data (constant means). Again, we found no satisfactory results (method shown in Visser and Petersen 2012, their figure 4), and for none of the cases could a satisfactory Kolmogorov-Smirnov test statistic be found $(\alpha=0.05)$.

Statistical trend techniques are therefore not appropriate for the data at hand. We therefore chose to give a trend presentation by fitting Lowess trends-a non-statistical robust trend technique. The trend estimates in Fig. 4 show that trends are more or less stable over time and not influenced by outliers. The only exceptions are global data over the 1980-1988 period. Our cautious, more qualitative, conclusion is that the trends in the number of people killed show constant, stabilized patterns over time.

\subsection{Overall conclusion}

Our overall conclusion from Figs. 3 and 4 is that normalized trends generally show stabilized, constant patterns, although some differences exist across the disaster impact indicators $L_{\mathrm{j}, \mathrm{t}^{\prime}}, A_{\mathrm{j}, \mathrm{t}}{ }^{\prime}$ and $K_{\mathrm{j}, \mathrm{t}}{ }^{\prime}$. With regard to economic losses, these results are consistent
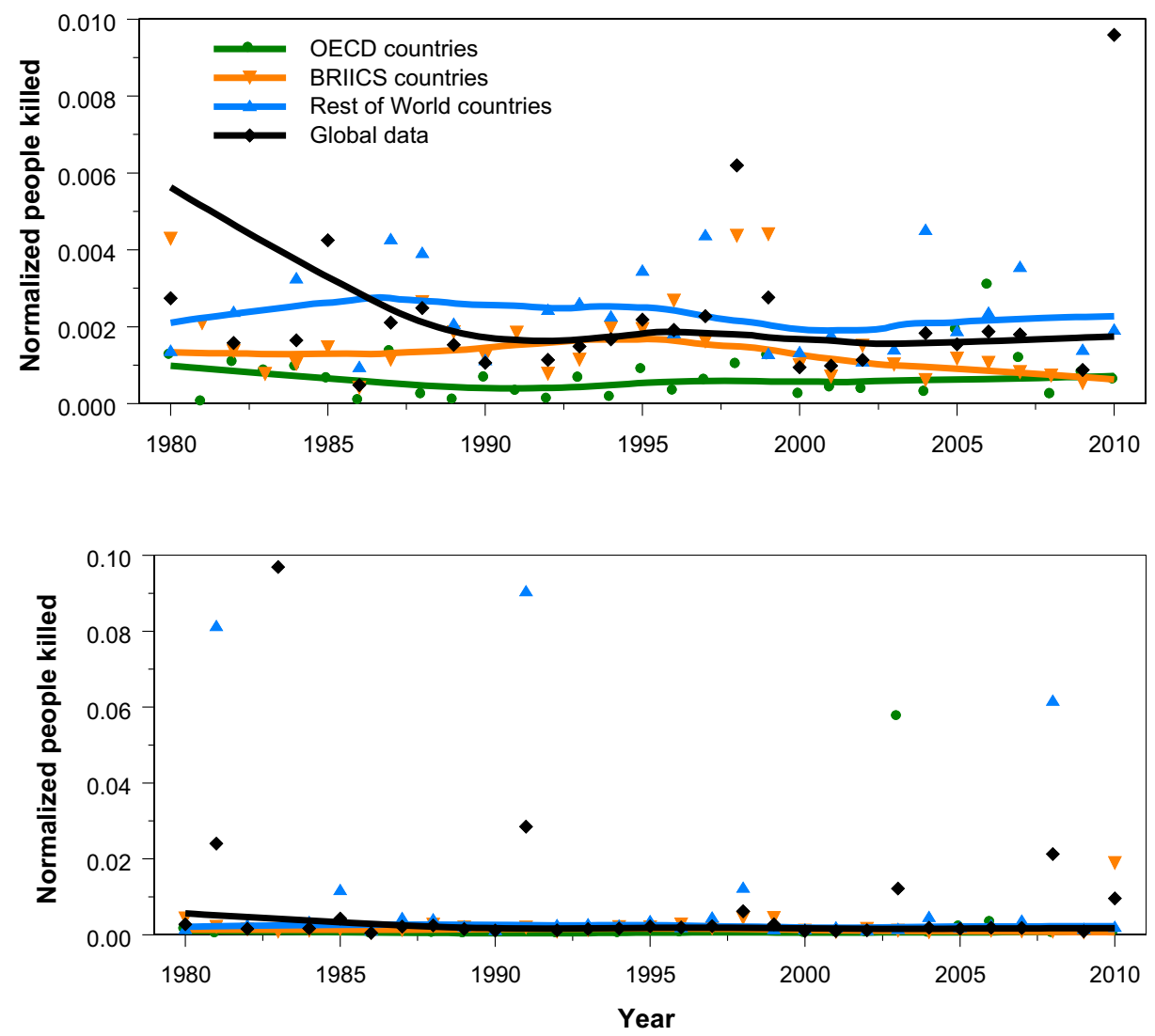

Fig. 4 Normalized number of people killed. The panels differ only by the $y$-axis range chosen. Sample period is 1980 to 2010. Trends are estimated by Lowess smoothing 
with those reported by Bouwer (2011a) for studies at the national level. Neumayer and Barthel (2011), reporting at the continental and global scales, also found stabilized losses (their figures 4 and 5, upper panels).

\section{The relative contribution of weather events and phenomena}

The normalized disaster impact indicators treated in Section 3 were aggregated for all types of weather extremes and phenomena. In the context of the 'Bouwer-Nicholls discussion' it is important to know the relative contribution of the various weather categories since trends in these have been studied in great detail (see Section 5). Here, we have aggregated weather events in three CRED categories: meteorological, hydrological and climatological events.

The relative contributions of these categories were calculated as follows: since each disaster in the EM-DAT database can be attributed to one of the three weather categories, we can rewrite economic losses simply as $L_{\mathrm{j}, \mathrm{t}}=L_{\mathrm{j}, \mathrm{Met}, \mathrm{t}}+L_{\mathrm{j}, \mathrm{Hyd}, \mathrm{t}}+L_{\mathrm{j}, \mathrm{Cli}, \mathrm{t}}$, with the abbreviations 'Met' for meteorological events, 'Hyd' for hydrological events, 'Cli' for climatological events and ' $\mathrm{j}$ ' the region of interest. By dividing the left and right hand parts by the term $W_{\mathrm{j}, \mathrm{t}}$ we arrive at normalized losses: $L_{\mathrm{j}, \mathrm{t}}{ }^{\prime}=L_{\mathrm{j}, \mathrm{Met}, \mathrm{t}}{ }^{\prime}+L_{\mathrm{j}, \mathrm{Hyd}, \mathrm{t}}{ }^{\prime}+L_{\mathrm{j}, \mathrm{Cli}, \mathrm{t}}{ }^{\prime}$. Since this equation is additive, we can take the arithmetic mean of both sides over the full sample period (1980-2010). This leads to the following relative contributions:

$$
\begin{aligned}
& \alpha_{\mathrm{j}, \text { Met }}=100 * \operatorname{mean}\left(L_{\mathrm{j}, \text { Met }, \mathrm{t}^{\prime}}\right) / \operatorname{mean}\left(L_{\mathrm{j}, \mathrm{t}}{ }^{\prime}\right)(\%) \\
& \alpha_{\mathrm{j}, \mathrm{Hyd}}=100 * \operatorname{mean}\left(L_{\mathrm{j}, \mathrm{Hyd}, \mathrm{t}}{ }^{\prime}\right) / \operatorname{mean}\left(L_{\mathrm{j}, \mathrm{t}}{ }^{\prime}\right)(\%) \\
& \alpha_{\mathrm{j}, \mathrm{Cli}}=100 * \operatorname{mean}\left(L_{\mathrm{j}, \mathrm{Cli}, \mathrm{t}}{ }^{\prime}\right) / \operatorname{mean}\left(L_{\mathrm{j}, \mathrm{t}}{ }^{\prime}\right)(\%)
\end{aligned}
$$

Clearly, the terms $\alpha_{\mathrm{j}, \mathrm{Met}}, \alpha_{\mathrm{j}, \mathrm{Hyd}}$ and $\alpha_{\mathrm{j} \text {, Cli }}$ add up to $100 \%$. Analogous to Eqs. (5a)-(5c), the $\alpha$ terms can be calculated for the number of people affected and the number of people killed.

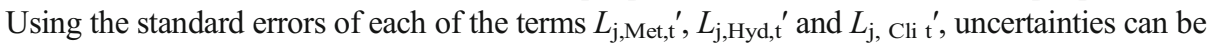
calculated for each $\alpha$ using the bootstrap technique (Efron 1982; details not given here).

All relative contributions are summarized in Table 1. We note that the table holds for normalized data; however, the percentages for non-normalized data are almost identical (exact percentages not given here).

\subsection{Economic losses $L_{\mathrm{j}, \mathrm{t}}$}

The upper panel of Table 1 shows a number of important differences across regions and weather categories. Firstly, climatological events have only a limited influence on economic losses $L_{\mathrm{t}}{ }^{\prime}$ : at the most they account for $17 \%$. Secondly, losses in OECD countries are dominated by meteorological events (64\%), which is not the case in BRIICS countries, where hydrological events dominate (66\%). Thirdly, meteorological and hydrological events are of equal weight (43 and $45 \%$ respectively) for the RoW countries. Finally, meteorological events dominate at the global scale $(50 \%)$. We note that the uncertainties in these percentages do not influence the inferences made previously (16 and 84 percentiles given in Table 1). 
Table 1 Contribution of specific types of weather extremes to the total of normalized disaster impact indicators, following Eqs. (5a)-(5c). The top panel is for economic losses, the middle panel for the number of people affected and the lower panel for the number of people killed. All data have been averaged over the 1980-2010 period and all columns sum to $100 \%$. Percentages between brackets are 68 confidence limits (based on 16 and 84 percentiles)

\begin{tabular}{|c|c|c|c|c|}
\hline Economic losses & OECD & BRIICS & Rest of World & Global \\
\hline $\begin{array}{l}\text { Cyclones and } \\
\text { storms }\end{array}$ & $\begin{array}{c}64 \% \\
{[57-70] \%}\end{array}$ & $\begin{array}{c}17 \% \\
{[13-21] \%}\end{array}$ & $\begin{array}{c}43 \% \\
{[37-49] \%}\end{array}$ & $\begin{array}{c}50 \% \\
{[45-55] \%}\end{array}$ \\
\hline Floods & $\begin{array}{c}21 \% \\
{[17-26] \%}\end{array}$ & $\begin{array}{c}66 \% \\
{[61-77] \%}\end{array}$ & $\begin{array}{c}45 \% \\
{[40-50] \%}\end{array}$ & $\begin{array}{c}35 \% \\
{[31-40] \%}\end{array}$ \\
\hline $\begin{array}{l}\text { Temperature } \\
\text { extremes, drought }\end{array}$ & $\begin{array}{c}15 \% \\
{[12-18] \%}\end{array}$ & $\begin{array}{c}17 \% \\
{[11-22] \%}\end{array}$ & $\begin{array}{c}12 \% \\
{[8-15] \%}\end{array}$ & $\begin{array}{c}15 \% \\
{[13-18] \%}\end{array}$ \\
\hline $\begin{array}{l}\text { All weather-related } \\
\text { events }\end{array}$ & $\begin{array}{c}100 \% \text { or } \\
0.0011 / \text { year }\end{array}$ & $\begin{array}{c}100 \% \text { or } \\
0.0014 / \text { year }\end{array}$ & $\begin{array}{c}100 \% \text { or } \\
0.0011 / \text { year }\end{array}$ & $100 \%$ \\
\hline
\end{tabular}

\begin{tabular}{|l|c|c|c|c|}
\hline $\begin{array}{l}\text { Number of people } \\
\text { affected }\end{array}$ & OECD & BRIICS & Rest of World & Global \\
\hline $\begin{array}{l}\text { Cyclones and } \\
\text { storms }\end{array}$ & $\begin{array}{c}36 \% \\
{[25-46] \%}\end{array}$ & $\begin{array}{c}8 \% \\
{[6-10] \%}\end{array}$ & $\begin{array}{c}30 \% \\
{[25-35] \%}\end{array}$ & $\begin{array}{c}12 \% \\
{[10-14] \%}\end{array}$ \\
\hline Floods & $43 \%$ & $65 \%$ & $56 \%$ & $63 \%$ \\
\hline $\begin{array}{l}\text { Temperature } \\
\text { extremes, drought }\end{array}$ & {$[31-54] \%$} & {$[57-74] \%$} & {$[56-70] \%$} \\
\hline $\begin{array}{l}\text { All weather-related } \\
\text { events }\end{array}$ & $\begin{array}{c}21 \% \\
{[11-33] \%}\end{array}$ & {$[18-35] \%$} & {$[8-19] \%$} & $25 \%$ \\
\hline
\end{tabular}

\begin{tabular}{|l|c|c|c|c|}
\hline $\begin{array}{l}\text { Number of people } \\
\text { killed }\end{array}$ & OECD & BRIICS & Rest of World & Global \\
\hline $\begin{array}{l}\text { Cyclones and } \\
\text { storms }\end{array}$ & $10 \%$ & $17 \%$ & $30 \%$ & $29 \%$ \\
\hline Floods & {$[6-36] \%$} & {$[11-23] \%$} & {$[11-49] \%$} & {$[17-48] \%$} \\
\hline $\begin{array}{l}\text { Temperature } \\
\text { extremes, drought }\end{array}$ & {$[4-23] \%$} & $48 \%$ & $6 \%$ & $11 \%$ \\
\hline $\begin{array}{l}\text { All weather- } \\
\text { related events }\end{array}$ & {$[35-62] \%$} & {$[3-11] \%$} & $60 \%$ \\
\hline
\end{tabular}

Gray fields show the highest percentage within each column

4.2 Number of people affected $A_{\mathrm{j}, \mathrm{t}^{\prime}}$

The middle panel of Table 1 shows a pattern quite different from that shown in the upper panel. For all four regions, the contribution from floods is most pronounced. Percentages range from $43 \%$ (OECD countries) to $65 \%$ (BRIICS countries). Meteorological events have some effect on disasters in OECD and RoW countries: 36 and $30 \%$ respectively. However, their influence in 
BRIICS countries and globally is small: 8 and $12 \%$ respectively. The influence of climatological events is rather limited, ranging from $14 \%$ (RoW countries) to $27 \%$ (BRIICS countries).

\subsection{Number of people killed $K_{\mathrm{j},{ }^{\prime}}$}

The lower panel of Table 1 shows that the percentages differ from those in the upper and middle panels. With regard to the number of people killed, climatological events dominate in three of the four regions: 84, 64 and $60 \%$ for OECD, RoW and global data respectively. The exception is the BRIICS countries. Here, the contribution is $35 \%$, which is lower than the influence of hydrological events (48\%), although uncertainties are wide in these two estimates.

\section{Are trends consistent?}

In the preceding sections, we estimated trends in normalized disaster indicators and analyzed the relative contribution of varying weather categories. Here, we return to the 'Bouwer-Nicholls discussion' described in Section 1: are the stabilized, constant patterns in normalized disaster burden indicators as shown in Figs. 3 and 4 consistent with trends in climate drivers and vulnerability (the terms $C_{\mathrm{t}}$ and $V_{\mathrm{t}}$ in Eq. 1)? As stated by Nicholls (2011), three situations could exist: (1) $C_{\mathrm{t}}$ is increasing and $V_{\mathrm{t}}$ decreasing, (2) $C_{\mathrm{t}}$ is decreasing and $V_{\mathrm{t}}$ increasing, or (3) both $C_{\mathrm{t}}$ and $V_{\mathrm{t}}$ show stabilized patterns over the sample period.

\subsection{Climate drivers}

Historic trend estimates for weather and climate variables and phenomena are presented in IPCC-SREX (2012, see their table 3-1). The categories 'winds', 'tropical cyclones' and 'extratropical cyclones' coincide with the 'meteorological events' category in the CRED database. In the same way, the 'floods' category coincides with the CRED 'hydrological events' category. The IPCC trend estimates hold for large spatial scales (trends for smaller regions or individual countries could be quite different).

The IPCC table shows that little evidence is found for historic trends in meteorological and hydrological events. Furthermore, Table 1 shows that these two events are the main drivers for (1) economic losses (all regions), (2) the number of people affected (all regions) and (3) the number of people killed (BRIICS countries only). Thus, trends in normalized data and climate drivers are consistent across these impact indicators and regions.

The IPCC categories 'temperature' and 'droughts' coincide with 'climatological events'. With regard to extreme temperatures, IPCC-SREX concludes that the number of hot extremes has increased since the 1950s, leading to an increase in fatalities; however, the number of cold extremes has decreased, leading to a decrease in fatalities. Furthermore, historic trends in the severity of droughts are unclear, although some regions have experienced more intense and longer droughts, in particular southern Europe and West Africa. Additionally, a more recent study by Sheffield et al. (2012) reports little change in global drought over the past 60 years.

It is difficult to say if, and how, these three different patterns 'cancel' each other out over large spatial scales. A positive trend in climatological events can not therefore be ruled out, which applies to those regions where climatological events play a dominant role (cf. lower 
panel of Table 1, the number of people killed in OECD countries, RoW countries and globally). The difficulty with estimating trends in $K_{\mathrm{j}, \mathrm{t}}{ }^{\prime}$ adds to that conclusion (cf. Figure 4).

We note that the IPCC-SREX conclusions on weather and climate extremes largely coincide with those drawn in IPCC (2007), except for tropical cyclones and droughts (Nicholls and Seneviratne 2013). For these events, the IPCC-SREX conclusions are more cautious; the same holds for conclusions drawn in IPCC (2013-see their sections 2.6.2.3, 2.6.3 and 2.6.4).

\subsection{Vulnerability}

As a direct consequence of the findings above, the third situation-both $C_{\mathrm{t}}$ and $V_{\mathrm{t}}$ show stabilized patterns over the sample period - should hold. In other words, this analysis shows that historic vulnerability is expected to be stable (constant) over the period of analysis. This conclusion is consistent with the reasoning of Bouwer (2011a); however, Nicholls points to a number of factors which should contribute to reductions in vulnerability, notably improvements in early warning systems (extreme weather forecasts) and improvements in building techniques. How can the constant vulnerability patterns therefore be explained?

This question is difficult to answer since quantitative information on vulnerability and vulnerability changes is sparse. Aon (2012) and BEH (2012) presented global vulnerability maps (the WorldRiskIndex), and Cutter et al. (2003) derived a social vulnerability index for the United States, but this did not include time-dependency. IPCC-SREX (2012, box 2-3) discussed vulnerability indices for the Americas, but these estimates are also static, and Preston et al. (2011) and Birkmann (2013) gave extensive reviews of vulnerability mapping.

Two recent developments in this field are however particularly worth mentioning. Preston (2013) presented an index for potential socio-economic exposure (PSE) that encompasses aspects of vulnerability. The PSE index is a function of both population and GDP changes and was derived for individual US counties. Also, Birkmann et al. (2014) presented 'socioeconomic pathways' (SSPs), which were derived for future developments in vulnerability but do not provide historic hindcasts.

More qualitatively, we give four explanations for the seemingly contradictory results found here, that of stabilized vulnerability patterns versus ongoing adaptation measures in many countries and regions (Adger et al. 2007, see their table 17.1; Nicholls 2011; Preston 2013, see their section 4; IPCC 2014). Firstly, global disaster management initiatives have only recently been put in place. The Hyogo Framework for Action (HFA) was adopted by 168 Member States of the United Nations in 2005 to take action to reduce vulnerabilities and risks to disasters (UNISDR, 2011). Although these highly important efforts will certainly pay off in the near future, it is unclear whether they are reflected in the sample period chosen for this study. Similar conclusions are drawn in IPCC (2014). The section on adaptation experience (SPM, A.2) sums up a number of adaptation examples across regions, but also states that 'adaptation is becoming embedded in some planning processes, with more limited implementation of responses (high confidence)'.

Secondly, it is unclear to what extent adaptation measures work in practice. Heffernan (2012) argues that many countries, and even the richest, are ill-prepared for weather extremes. As an example, he names Hurricane Sandy, which wreaked a loss of 50 billion USD along the northeast coast of the US in 2012. As for early warning systems, Heffernan states that not all systems are functioning well. For example, in 2000, Mozambique was hit by a flood worse than any in its history, and the event was not at all anticipated. Warnings of above-average rainfall came too late and failed to convey the magnitude of the coming flood. 
Thirdly, a positive trend in vulnerability may be offset by the increasing number of people moving from rural to urban environments, often situated in at-risk areas (UN 2012). Since many large cities lie along coastlines, these movements will make people more vulnerable to land-falling hurricanes (Pielke et al. 2008), coastal flooding and heatwaves (due the urban heat island effect). With regard to economic losses, Hallegatte (2011) argues that these migration movements may have caused disaster losses to grow faster than wealth.

Fourthly, it is unclear how political tensions and violent conflicts have evolved over large regional scales since 1980. On the one hand, Theisen et al. (2013) show that the number of armed conflicts and the number of battle deaths have decreased slightly at the global scale since 1980. On the other hand, these methods are rather crude as far as covering all aspects of political tensions are concerned (Leaning and Guha-Sapir et al. 2013).

We conclude that quantitative information on time-varying vulnerability patterns is lacking. More qualitatively, we judge that a stable vulnerability $V_{\mathrm{t}}$, as derived in this study, is not in contrast with estimates in the literature.

\section{Future disaster impacts}

Estimates of future disaster impacts are sparse in the literature, though they may be found in Maaskant et al. (2009), Jongman et al. (2012) and Bouwer (2013), for example. The findings presented in the preceding section may have implications for the coming decades, at least if we assume the terms $C_{\mathrm{t}}$ and $V_{\mathrm{t}}$ to be stable. If so, we can use projections for exposure ( $W_{\mathrm{t}}$ and $\left.P_{\mathrm{t}}\right)$ as predictors for disaster impacts $D_{\mathrm{t}}$, as can be seen from Eqs. (3a)-(3c). The following projections are given by OECD (2012) for the 2010-2050 period:

- Growth in GDP: $140 \%$ in OECD countries, $520 \%$ in BRIICS countries and $410 \%$ in RoW countries

- Population growth: an increase of $10(-3,23) \%$ in OECD countries, $17(6,34) \%$ in BRIICS countries and $65(30,80) \%$ in RoW countries - medium, low and high variants taken from UN (2009)

Thus, given the relations in Eqs. (3a)-(3c), we can use these GDP projections for economic losses and the population projections for the number of people affected or killed.

Clearly, these projections are hampered by uncertainties in $C_{\mathrm{t}}$ and $V_{\mathrm{t}}$, although projections for meteorological and hydrological events up to 2100 tend to be stable (IPCC-SREX, 2012, see their table 3-1). The term $V_{\mathrm{t}}$ is the 'great unknown' here (arguments similar to those given in Section 5), and the emerging relation between climate change, economic growth and violent conflicts will make predictions even more difficult (Bergholt and Lujala 2013; Solow 2013; IPCC 2014, SPM, B.2).

We therefore believe that disaster impact projections can be given for the short term only (up to the year 2030). For this 20-year time horizon, increases in economic losses become $70 \%$ for OECD countries, $260 \%$ for BRIICS countries and $210 \%$ for RoW countries. Projections for the number of people affected and the number of people killed show an increase of $5(-1,12) \%$ for OECD countries, $8(3,17) \%$ for BRIICS countries and $33(15$, $40) \%$ for RoW countries.

We note that Preston (2013) follows a slightly different approach using economic loss data for counties in the United States, as described in Section 5. He presents losses on a county scale for the years 2025 and 2050, while assuming climate to be stable over time. 


\section{Summary and conclusions}

We analyzed disaster impact data in a 3 by 4 by 3 framework based on the CRED EM-DAT database: (1) three disaster impact indicators: economic losses, the number of people affected and the number of people killed, (2) four regions: global, OECD countries, BRIICS countries and remaining countries, and (3) three categories of extreme weather and climate events: meteorological, hydrological and climatological events. Our analysis consisted of data normalization by correcting for changes in wealth (taken as GDP) and population. Trends in these normalized data were compared with trends in the drivers of disaster burden, which are extreme weather events and phenomena, and vulnerability.

We draw the following conclusions:

- Trends in normalized data show constant, stabilized patterns in most cases (Figs. 2, 3 and 4), a result consistent with findings reported in Bouwer (2011a) and references therein, Neumayer and Barthel (2011) and IPCC-SREX (2012).

- The role of weather-related drivers varies strongly over economic regions and disaster burden indicators (Table 1). For normalized economic losses, the main drivers are meteorological and hydrological events, whereas climatological events play a minor role. For normalized numbers of people affected, hydrological events are dominant in all regions. For the number of people killed, climatological events are dominant.

- The absence of trends in normalized disaster burden indicators appears to be largely consistent with the absence of trends in extreme weather events. This conclusion is more qualitative for the number of people killed. As a consequence, vulnerability is also largely stable over the period of analysis. Possible explanations have been discussed.

- We used the findings for historic data to project disaster impacts for the coming decades. A projection for economic losses over the 2010-2030 period yields an increase of $70 \%$ in OECD countries, $260 \%$ in BRIICS countries and $210 \%$ in RoW (Rest of World) countries. Projections for both the number of people affected and the number of people killed show an increase of $5(-1,12) \%$ in OECD countries, $8(3,17) \%$ in BRIICS countries and $33(15,40) \%$ in RoW countries.

Acknowledgements We would like to thank Bert de Vries (University of Utrecht, the Netherlands), Laurens Bouwer (Deltares, the Netherlands) and two anonymous reviewers for helpful comments on the manuscript. The Centre for Research on the Epidemiology of Disasters (CRED) of the Universite Catholique de Louvain is thanked for making available the EM-DAT database (www.emdat.be).

Open Access This article is distributed under the terms of the Creative Commons Attribution License which permits any use, distribution, and reproduction in any medium, provided the original author(s) and the source are credited.

\section{References}

Adger WN, Agrawala S, Mirza MMQ, Conde C, O’Brien K, Pulhin J, Pulwarty R, Smit B, Takahashi K (2007) Assessment of adaptation practices, options, constraints and capacity. In: IPCC report: Climate change 2007: impacts, adaptation and vulnerability, IAEA, Geneva, pp 717-743

Aon (2012) Aon political risk map. Available at:http://www.aon.com/risk-services/political-risk-map2/map/ Interactive_Risk_Map/2011_Political_Risk_Map/index.html. Accessed June 2014 
Barthel F, Neumayer E (2012) A trend analysis of normalized insured damage from natural disasters. Clim Change 113:215-237

BEH (2012) World risk report 2012. United Nations University (EHS). Bündnis Entwicklung Hilft, Berlin

Below R, Wirtz AW, Guha-Sapir D (2009) Disaster category classification and peril terminology for operational purposes. CRED-MunichRE working paper 264, CRED, Brussels

Bergholt D, Lujala P (2013) Climate-related natural disasters, economic growth, and armed conflict. J Peace Res 49(1):147-162

Birkmann J (ed) (2013) Measuring vulnerability to natural hazards. United Nations University Press, Tokyo

Birkmann J, Cutter SL, Rothman DS, Welle T, Garschagen M, van Ruijven B, O'Neill B, Preston BL, Kienberger S, Cardona OD, Siagian T, Hidayati D, Setiadi N, Binder CR, Hughes B, Pulwarty R (2014) Scenarios for vulnerability: opportunities and constraints in the context of climate change and disaster risk. Climatic Change doi:10.1007/s10584-013-0913-2

Bouwer LM (2011a) Have disaster losses increased due to anthropogenic climate change? BAMS 92(1):39-45

Bouwer LM (2011b) Comments on "Have disaster losses increased due to anthropogenic climate change?": reply. BAMS 92(6):792-793

Bouwer LM (2013) Projections of future extreme weather losses under changes in climate and exposure. Risk Anal 33(5):915-930

Chandler RE, Scott EM (2011) Statistical methods for trend detection and analysis in the environmental sciences. Wiley, Chichester, UK

Coles S (2001) An introduction to statistical modeling of extreme values. Springer, Heidelberg, Germany

Cutter SL, Boruff BJ, Shirley WL (2003) Social vulnerability to environmental hazards. Soc Sci Q 84(2):242-261

Efron B (1982) The jackknife, the bootstrap and other resampling plans. Regional Conference Series in Applied Mathematics, Philadelphia, PA

Guha-Sapir D, Vos F, Below R, Ponserre S (2012) Annual disaster statistical review 2011: the numbers and trends. Brussels, CRED, Brussels

Hallegatte S (2011) How economic growth and rational decisions can make disaster losses grow faster than wealth. World Bank policy research working paper 5617, World Bank, Washington, DC

Heffernan O (2012) No going back. Nature 491:659-661

IPCC (2007) Climate Change 2007: the physical science basis. Working Group I contribution to the Fourth Assessment Report of the Intergovernmental Panel on Climate Change. Cambridge University Press, Cambridge

IPCC (2013) Climate Change 2013: the physical science basis. Working Group I contribution to the Fifth Assessment Report of the Intergovernmental Panel on Climate Change. Cambridge University Press, Cambridge

IPCC (2014) Climate Change 2014: impacts, adaptation, and vulnerability. Working Group II contribution to the Fifth Assessment Report of the Intergovernmental Panel on Climate Change. Available at: http://www.ipcc. $\mathrm{ch} /$. Accessed June 2014

IPCC-SREX (2012) Managing the risks of extreme events and disasters to advance climate change adaptation, IPCC special report. Available at: http://ipcc-wg2.gov/SREX. Accessed June 2014

Jongman B, Ward PJ, Aerts JCJH (2012) Global exposure to river and coastal flooding: long-term trends and changes. Glob Environ Change. doi:10.1016/j.gloenvcha.2012.07.004

Leaning J, Guha-Sapir D (2013) Natural disasters, armed conflict, and public health. N Engl J Med 369:1836

Maaskant B, Jonkman SN, Bouwer LM (2009) Future risk of flooding: an analysis of changes in potential loss of life in South Holland (The Netherlands). Environ Sci Pol 12:157-169

Neumayer E, Barthel F (2011) Normalizing economic loss from natural disaster: a global analysis. Glob Environ Change 21:13-24

Nicholls N (2011) Comments on "Have disaster losses increased due to anthropogenic climate change?". BAMS 92(6):791-791

Nicholls N, Seneviratne SI (2013) Comparing IPCC assessments: how do the AR4 and SREX assessments of changes in extremes differ? Clim Change. doi:10.1007/s10584-013-0818-0

OECD (2012) OECD environmental outlook to 2050. OECD, Paris

Pielke RA Jr, Gratz J, Landsea CW, Collins D, Saunders MA, Musulin R (2008) Normalized hurricane damage in the United States: 1900-2005. Nat Haz Rev 9(1):29-42

Preston BL (2013) Local path dependence of U.S. socioeconomic exposure to climate extremes and the vulnerability commitment. Glob Environ Change 23:719-732

Preston BL, Yuen EJ, Westaway RM (2011) Putting vulnerability to climate change on the map: a review of approaches, benefits, and risks. Sustain Sci 6:177-202

Sheffield J, Wood EF, Roderick ML (2012) Little change in global drought over the past 60 years. Nature 491: $435-438$ 
Solow AR (2013) A call for peace on climate and conflict. Nature 497:189-190

Theisen OM, Gleditsch NP, Buhang H (2013) Is climate change a driver of armed conflict? Clim Change 117(3): 613-625 :

UN (2009) World urbanization prospects, the 2008 Revision. Final report with annex tables. United Nations, New York

UN (2012) World Urbanization Prospects, the 2011 Revision. Final report with annex tables. United Nations, New York

UNISDR (2011) Global Assessment Report of disaster risk reduction, Geneva, Switzerland, United Nations International Strategy for Disaster Reduction. Website: http://www.unisdr.org/we/coordinate/hfa. Accessed June 2014

Visser H (2004) Estimation and detection of flexible trends. Atmos Environ 38:4135-4145

Visser H, Petersen AC (2012) Inferences on weather extremes and weather-related disasters: a review of statistical methods. Clim Past 8:265-286

Visser H, Bouwman A, Petersen AC, Ligtvoet W (2012) A statistical study of weather-related disasters: past, present and future. PBL research report 555076001, PBL, Bilthoven, The Netherlands. Available at: http:// www.pbl.nl/sites/default/files/cms/publicaties/PBL_2012_Weather\%20Disasters_555076001_0.pdf. Accessed June 2014 